\title{
POLÍTICAS PÚBLICAS BRASILEIRAS E PRÁTICAS DEMOCRÁTICAS DE DIRETORES ESCOLARES
}

\author{
BRAZILIAN PUBLIC POLICIES AND DEMOCRATIC PRACTICES OF SCHOOL \\ DIRECTORS
}

\author{
Maria Cecília LUIZ ${ }^{1}$ \\ Ronaldo Martins GOMES ${ }^{2}$ \\ Cristina de Cássia M. da SILVA ${ }^{3}$
}

RESUMO: Refletimos sobre a importância das práticas democráticas como processo e seu significado no âmbito educacional, a partir de relatos de alguns diretores escolares. A parte empírica foi realizada em uma cidade de médio porte, localizada no interior de São Paulo. Estabeleceu-se uma amostra de dez escolas municipais cada uma com seus respectivos gestores e efetuamos entrevistas semiestruturadas, com intuito de verificar em que medida eles criavam práticas democráticas e em que espaços, segundo os seus pontos de vista. Apresentamos três categorias: espaços democráticos e a política da escola; a democracia na visão dos diretores de escola; e, políticas educacionais e gestão democrática. Ao analisarmos os relatos e práticas dos diretores concluímos que estes, buscavam gerir a escola com perspectivas democráticas. Estas práticas são bastante criativas como foi o caso da política do cafezinho.

PALAVRAS-CHAVE: Diretores de escola. Políticas Públicas Brasileiras. Gestão democrática. Participação.

ABSTRACT: We reflect on the importance of democratic practices as a process and its significance in the educational field, from some school directors reports. The empirical part was carried out in a Brazilian medium-sized city, located in São Paulo, Brazil. Established a sample of ten municipal schools each with their respective managers and we made semistructured interviews in order to verify to what extent they created democratic practices and spaces where, according to their views. We present three categories: democratic spaces and school policy; democracy in the eyes of school principals; and, educational and democratic management policies. When analyzing the reports and practices of directors concluded that these in some way, sought to manage the school with democratic prospects. These practices are quite creative as was the case with the politics of coffee.

KEYWORDS: School Directors. Brazilian public policies. Democratic management. Participation.

\footnotetext{
${ }^{1}$ Doutora em Educação. Professora Associada da Universidade Federal de São Carlos/UFSCar SP/ Brasil ${ }^{2}$ Mestre em Educação; Doutorando em Educação do Programa de Pós- Graduação da UFSCar/SP/Brasil

${ }^{3}$ Mestre em Educação na área de Políticas Públicas pela UNICID/SP/Brasil. Diretora Técnica III do Departamento de Programas de Formação e Educação Continuada na Escola de Formação e Aperfeiçoamento dos Professores do Estado de São Paulo "Paulo Renato Costa e Souza".
} 


\section{Introdução}

No Brasil, por meio de significativas mobilizações sociais, a partir da década de 1980, houve o despertar de uma nova conjuntura política com características fortes de redemocratização da sociedade, que teve como ápice a Constituição Federal Brasileira de 1988. Nessa nova legislação o discurso da participação ganha relevância, e a educação começam a ser vista como direito fundamental, com o propósito de superar as desigualdades sociais e a exclusão. Na mesma direção foram promulgados o Estatuto da Criança e do Adolescente (ECA - Lei $n^{\circ}$ 8.069/90) e a Lei de Diretrizes e Bases da Educação Nacional (LDB - Lei $n^{\circ}$ 9.394/96), de maneira que estas assegurassem o direito à educação, com garantia de igualdade de condições para o acesso e permanência de todos na escola.

Devido aos apelos de redemocratização, a sociedade brasileira desperta para a necessidade de rever a função social da escola e seus objetivos, assim como refletir sobre suas práticas e avaliações. Neste aspecto, tornou-se necessário a descentralização da gestão escolar, com perspectivas mais democráticas e a garantia de participação da equipe gestora, professores, de funcionários, de alunos e seus pais nas decisões da escola, por meio de colegiados. O modelo de administração escolar pautado no autoritarismo e centralizado na figura do diretor da escola não correspondia mais às expectativas, por isso deveria ser substituído aos poucos por uma gestão democrática, com possibilidade de obter participação de todos nas decisões e na efetivação de ações de forma colaborativa, e não como algo imposto de forma hierárquica.

É nesse contexto que a formação para diretores esteve fortemente presente nas Secretarias de Educação do país, contribuindo assim para que os educadores que já estavam inseridos na escola pudessem conhecer diferentes ideias, construir novos conhecimentos, repensar suas práticas de forma reflexiva e crítica. Era relevante que a equipe gestora reconsiderasse a gestão e organização da escola com a perspectiva da participação, com vistas a contribuir para a melhoria do seu trabalho e consequentemente da aprendizagem de seus estudantes.

Quando analisamos a organização escolar, estamos evidenciando o todo da escola, isto significa compreender as concepções de educação, os fenômenos de liderança, os jogos de poder, quem são os sujeitos, em que tempo e espaço, assim como, também, do contexto social, político, econômico, cultural em que esta está inserida. 
Portanto, são muitas as variáveis que nos remetem à identidade e à singularidade das escolas.

Este artigo é fruto de uma investigação feita de práticas e vivências de alguns diretores de escolas municipais, com o objetivo de compreender a relação entre escola pública e democracia, isto é, refletir sobre essas mudanças, iniciadas na década de 1980, com a meta de compreender como a gestão democrática estava se efetivando na prática, depois da redemocratização das decisões no âmbito das relações escolares.

Nessa perspectiva buscamos refletir sobre a importância das práticas democráticas como processo e seu significado no âmbito educacional, a partir de relatos de alguns diretores de escola. Para a parte empírica foi selecionada uma cidade de médio porte, localizada no interior de São Paulo. Neste momento de coleta dos dados, a Secretaria Municipal de Educação dispunha de cento e sessenta e quatro (164) unidades escolares, desse total, estabeleceu-se uma amostra de dez escolas municipais cada uma com seus respectivos gestores: duas (2) escolas de Ensino Fundamental séries iniciais; uma (1) escola de Ensino Fundamental séries iniciais e finais; uma (1) escola de Ensino Fundamental séries iniciais e EJA I e II; uma (1) escola de Educação Infantil (3 a 5 anos), Ensino Fundamental séries iniciais e EJA I e II; duas (2) escolas de Educação Infantil (4 meses e 3 anos), sendo que uma delas atendia em tempo integral; três (3) escolas de Educação Infantil (3 a 6 anos), inclusive uma delas atendia tempo integral.

Efetuamos entrevistas semiestruturadas com esses dez diretores com o intuito de verificar em que medida eles criavam práticas democráticas e em que espaços, isto é, como essas práticas ocorriam em suas escolas, segundo os seus pontos de vista. Com o foco voltado para as atuações de gestores e suas práticas no cotidiano escolar, intentávamos identificar, em suas visões, como eles acreditavam que estavam realizando práticas democráticas. A ideia era realizar uma formação continuada para todos os diretores municipais dessa cidade, depois dos resultados dessa pesquisa, que suscitasse reflexões sobre uma administração escolar fundada no coletivo, na qual os propósitos estivessem subsidiados na representatividade de diferentes segmentos de dentro e de fora da escola.

O termo gestão democrática foi aqui utilizado com vistas a ampliar a dimensão do trabalho do diretor de escola, considerando a democratização, a participação e a construção do processo pedagógico, a partir da articulação de ações na escola. O conceito de democracia, termo polissêmico, teve como base autores como: Habermas (1995, 2002, 2003 e 2010), Elster (2001) e Mármol (2001). A busca pelo 
aprofundamento das relações entre escola pública e democracia nos possibilitou entender um pouco melhor as concepções e práticas de alguns diretores de um município brasileiro.

Para Sartori (1993), existe a democracia como ideal e como prática social. Isso implica em defini-la como prescritiva e descritiva. Desta forma, buscou-se não se confundir o ideal democrático (democracia prescritiva) com as práticas do real democrático (democracia descritiva). Ambas as definições nem sempre acontecem de forma conjunta, sendo que as experiências democráticas maduras acabam suscitando conflitos em suas formas de convivência. Por isso o que caracteriza uma democracia não é o consenso, mas o dissenso que mantém transparente as relações sociais, políticas e econômicas.

Outro aspecto importante foi compreender que o conceito de democracia, muitas vezes, tem ocultado os malefícios do sistema capitalista, com suas políticas de ajuste estrutural, privatização e a completa vulnerabilidade da subordinação das economias ao capital financeiro especulativo, além de possuir um caráter centralizador para a educação. A educação, mais especificamente, a escola, carrega consigo a responsabilidade de possibilitar igualdade de oportunidades, caindo sobre ela a obrigação de realizar uma formação competitiva, com ênfase na aquisição de conhecimentos e habilidades cognitivas comportamentais.

No contexto neoliberal, a educação é concebida como "salvadora da pátria" e essa concepção redireciona o pensar e o fazer político-pedagógico. Para entendermos melhor as políticas públicas educacionais brasileiras e o significado de democracia, temos que entender como se constituiu o processo de formação do Estado e de suas políticas, com vistas a visualizarmos algumas de suas particularidades.

\section{Sistema Político Brasileiro: contextualizando a realidade}

Segundo Schwartzman (1988), sistema político é a arena em que os escassos recursos existentes no Estado são disputados por classes, grupos e instituições com vistas à apropriação e utilização do poder econômico e, principalmente do político. Desta forma, antes de discorrermos sobre o tema, é importante ressaltar que dois grandes equívocos podem ocorrer quando falamos de democracia: um primeiro, está em entender esse processo como uma extensão do conceito de dignidade democrática da 
polis grega. A diferença entre a política antiga e a moderna é notável (HABERMAS, 1997), e entre essa dessemelhança está o conceito de liberdade e de soberania.

Para Constant (1985), a liberdade dos antigos baseava-se no exercício da soberania pública, igualmente dividida entre todos os cidadãos (homem público), que abertamente debatiam e decidiam a respeito das direções que a pólis deveria seguir; a ideia consistia em garantir o direito e a partilha do poder social. Já o conceito de liberdade para os modernos funda-se na perspectiva de ação de forma indireta e representativa (homem particular), por meio de indivíduos e instituições reconhecidos e eleitos no âmbito público sob a égide estatal, cuja intenção é assegurar a propriedade e as necessidades privadas.

O objetivo dos antigos era a partilha do poder social entre todos os cidadãos de uma mesma pátria. Era isso o que eles denominavam liberdade. O objetivo dos modernos é a segurança dos privilégios privados; e eles chamam liberdade às garantias concedidas pelas instituições a esses privilégios (CONSTANT, 1985, p. 15-16).

Enquanto na antiguidade existia a dependência do cidadão com relação à pólis, uma vez que a participação na vida pública era considerada o ápice da existência humana, sendo fundamental, diferentemente da vida privada (ARISTÓTELES, 1988). Na política da modernidade tal situação não se ajusta, uma vez que a individualidade acaba com o ideal de coletividade clássica:

O que diferencia de modo radical a situação política da modernidade relativamente à pólis grega é o surgimento da individualidade moderna, determinante último da desaparição da unidade imediata e transparente dos indivíduos com a vida comunitária (TORRES, 1989 p. 26).

O segundo grande erro é achar que a política brasileira foi constituída apenas pelo processo de formação do Estado moderno europeu (como na França e Inglaterra, por exemplo). Para Torres (1989), a noção de liberdade e representatividade política está diretamente vinculada ao processo de "abstração do Estado em sua dimensão racional-legal" (p. 46), que se formalizou definitivamente com o amadurecimento de três características básicas: soberania, despersonalização e despatrimonialização do poder.

Diferentemente da Europa, no Brasil a racionalidade formal e o ordenamento legal, que são características fundamentais do Estado e da administração moderna não foram evidentes nas características formativas do Estado brasileiro. Na Europa 
Ocidental a democracia se formou no contexto do liberalismo com as funções do Estado organizadas para manter uma ordem jurídica impessoal e universal, com possibilidades de empreendimento e desenvolvimento para os agentes econômicos, com perspectivas nos planos pessoal e profissional.

O legado português estabeleceu um Estado dirigista ao Brasil, com características de planejar e intervir na economia, dando privilégios para grupos que permaneciam no controle. Desta maneira, o patrimonialismo fez parte da realidade brasileira desde o processo de colonização, acentuando-se no império, e propagando-se na República.

A realidade histórica brasileira demonstrou (...) a persistência secular da estrutura patrimonial, resistindo galhardamente, inviolavelmente, à repetição, em fase progressiva da experiência capitalista. Adotou do capitalismo a técnica, as máquinas, as empresas, sem aceitar-lhe a alma ansiosa de transmigrar. (FAORO, 2001, p. 822).

O Brasil não segue a mesma lógica no processo formativo do Estado moderno europeu. O mesmo vale para outros países que se formaram a partir do início da modernidade. Nesse sentido, esses Estados não possuem a mesma lógica e dinâmica das democracias surgidas há não mais de duzentos anos, após as revoluções americanas [1776] e francesas [1789].

Segundo Swchartzman (1988), o Estado moderno brasileiro é chamado de "neopatrimonial", pois diferentemente da Europa Ocidental - em que esteve presente uma burguesia forte e determinante para o conjunto geral da sociedade - no Brasil essa burguesia não existiu, pelo menos com tais características. O Estado brasileiro (Ibidem, 1988) sempre teve uma burocracia pesada, com muito poder, mas pouco eficiente e ágil. Além disso, a sociedade brasileira ficou sem tradição de articulação e representação política, pois ficou rendida diante de um Estado que possuía todo poder e se considerava na função de "regulador".

Para Vianna (1987), a colonização portuguesa deixou para o Brasil uma perspectiva de patriarcalismo, de cunho ruralista, arbitrário, cujas consequências mais marcantes foram: inexistência de uma consciência nacional, suposta onipotência do Estado, e originou a cultura da patronagem e do clientelismo. Uricoechea (1978), também defende a ideia desse hibridismo na política do Estado brasileiro, devido à junção de elementos modernos com formas tradicionais de governo, por meio de cooptações com o poder local. Assim, a política brasileira adequou a herança 
burocrática português a cooptação administrativo local, constituindo uma formação híbrida própria. Uricoechea (1978) indica o surgimento de uma "burocracia patrimonial”.

Podemos definir os processos estratégicos do Estado patrimonial brasileiro em: cooptação, clientelismo, coronelismo e mandonismo. Trata-se de processos patrimonialistas, que ao contrário do processo de despatrimonialização e despersonalização, acabam por confundir as esferas públicas e privadas. Neste aspecto, a formação de um Estado abstrato não acontece, já que boa parte das instâncias burocráticas da administração estatal atende aos interesses privados.

Segundo Carvalho (1996), para manter essa estrutura burocrática complicada que vai do nacional ao local, o Estado brasileiro estabelece compromissos e cooptações com as políticas locais. Para Leal (1975), existem relações entre o regime político representativo e as lideranças locais, cooptadas por privilégios políticos em troca de eleitores locais. Neste sentido, denomina-se coronelismo a troca de favores entre poder público e forças políticas locais:

Por isso mesmo, o 'coronelismo' é sobretudo um compromisso, uma troca de proveitos entre o poder público, progressivamente fortalecido, e a decadente influência social dos chefes locais, notadamente dos senhores da terra. (LEAL, 1975, p. 20).

A imagem do coronel é muito mais significativa do que um representante político, pois representa a figura paternalista e patrimonialista da liderança local. Serviços assistencialistas como: alimentação, remédios, oportunidade de emprego etc., acontecem por meio das ações desta celebridade e, é por isso que sua importância é mais significativa para a população mais pobre, afinal, tudo depende do coronel. Há uma espécie de reciprocidade entre coronel e poder público. Para Leal (1975), o coronelismo é fruto de um empobrecimento político e se apropria da cruel vantagem que tira de famílias menos favorecidas que sobrevivem da sua dependência.

Uma consequência dessa forma de organizar a política local é agenciar favores pessoais, que resulta na incapacidade administrativa, principalmente dos municípios, devido à política de indicações de cargos de confianças nos setores públicos. Essa perspectiva pode agravar-se, pois a ausência do poder público no município aumenta cada vez mais o poder do coronel, principalmente, pela falta de grupos políticos que representem os interesses dos cidadãos. Essa política do coronelismo é facilmente identifica nas relações entre Secretarias de Educação (poder local municipal) e diretores 
de escola.

Para Lima (2011), com a análise multifocalizada para a compreensão das organizações escolares é possível discutir limites e potencialidades de ações formativas e de práticas democráticas de diretores escolares. No aspecto da ação organizacional, a participação praticada nas escolas permite vários níveis de análise: a democraticidade, a regulamentação, o envolvimento e a orientação. Ao considerarmos que a participação e a não participação no âmbito da escola são variáveis extremamente complexas e dinâmicas na análise das organizações institucionais e na atuação dos gestores escolares, e que essas podem estar sendo determinadas por contextos de um período de tempo e/ou espaço, e interligadas.

Entendemos que existem opções e posicionamentos que são frutos de políticas, concepções, ideias, crenças, histórias de vida, interesses coletivos e/ou pessoais, dentre outros. Ao analisarmos as políticas educacionais brasileiras e suas características peculiares que foram constituídas por um contexto histórico, podemos afirmar que requerer o engajamento e o envolvimento de cidadãos brasileiros nos processos de tomada de decisões, com vistas a uma gestão democrática, segundo autores como: Habermas (1995, 2002, 2003 e 2010), Elster (2001) e Mármol (2001), é de suma importância, mas, extremamente complexo, somente possível vias procedimentos processuais.

Como já dissemos no início deste texto, a democracia no Brasil vem sendo retomada desde a década de 1980 , e trouxe novas possibilidades de participação nas políticas públicas e nas tomadas de decisão que afetavam a vida coletiva, assim, aspectos relacionados à organização do trabalho da gestão escolar mostrou-se elemento facilitador na construção da autonomia e da participação coletiva na unidade escolar. Nesse contexto, o diretor de escola, seus conhecimentos a respeito de processos organizacionais, de currículo e metodologias de ensino, da cultura e realidade local, articulados aos procedimentos dialógicos, participativos, coletivos, são de fundamental importância para a construção da autonomia da/na escola. A seguir analisamos as três principais categorias que evidenciamos neste estudo.

\section{Espaços democráticos e a política da escola}

Ao evidenciarmos os espaços democráticos e a política da escola, organizamos 
uma primeira categoria, "espaços democráticos e a política da escola" que nos permitiu a compreensão de como e quais momentos eles aconteciam, e como era o olhar dos diretores a respeito da perspectiva da gestão democrática. Por espaços democráticos, neste trabalho, entende-se o lugar em que acontece a participação dos agentes envolvidos com as demandas do dia a dia escolar: gestores, docentes, discentes, funcionários (contratados e terceirizados), familiares e/ou responsáveis por estudantes e a comunidade de entorno, por meio de deliberação igualitária (HABERMAS, 1995), em que status social, formação ou qualquer outro fator de distinção social não prevalece enquanto força de argumento. A força do argumento, por menos ilustrado que seja o seu proferido, reside sim, na defesa do interesse coletivo (a escola).

Nessa perspectiva, a construção dos espaços democráticos na escola se fundamenta no diálogo participativo como método de desenvolvimento de respostas às demandas específicas surgidas no dia a dia escolar. A participação tende a fortalecer as relações sociais que se dão por meio do diálogo argumentativo, e isso cria potencialmente atitudes e qualidades psicológicas nos sujeitos, na perspectiva de se comprometerem com os objetivos comuns da e na escola, em determinadas circunstâncias.

A democracia na escola, mediada pela gestão, só acontece em ambientes democráticos que se caracterizam pela participação efetiva de todos os envolvidos com a escola. As práticas como seleção das atividades de natureza pedagógica; reflexões e análises sobre o desenvolvimento da aprendizagem das classes e salas; a construção a partir do diálogo argumentativo de soluções para as demandas concretas do dia a dia escolar; etc. são objetos da gestão escolar que devem ser tratados em espaços democráticos, como: Horas de Trabalho Pedagógico Coletivo - HTPC; reuniões do Conselho Escolar e de pais ou responsáveis; reuniões da Associação de Pais e Mestres APM etc.

São esses ambientes propícios em que a escola tem a oportunidade de vivenciar e estimular a democracia descrita nos livros, muito embora isso não signifique uma aplicação de forma direta e simples dos conteúdos que tratam da democracia na realidade imediata escolar. É importante resgatar aqui a perspectiva de Sartori (1993) diferenciando modelos descritivos e prescritivos, no sentido de se aplicar, nos limites da realidade escolar, os princípios do que poderia ser discutido e debatido com os estudantes. Nesse caso, uma gestão escolar que se constitua de forma democrática se 
tornaria um exemplo prático, dando oportunidade para os estudantes compreenderem uma realidade estendida para políticas municipais, estado federado, e mesmo do país.

Um dos pontos que se destacou na investigação é a importância da atuação no âmbito da responsabilidade profissional, como destaca este gestor:

Mas na medida do possível, aqui prezamos pelo direito à fala, pelo diálogo e a democracia. Cada um tem que respeitar o outro e também de falar o que pensa e principalmente as pessoas que estão na função, que sabem o que funciona e o que não funciona. Então eu, como gestora da escola, tenho que ouvi-las para saber administrar, para saber o que vai dar certo e o que não vai dar, eu acredito nisso [Gestor da Escola 4].

Há um forte destaque também para o trabalho em conjunto que é uma das características fundamentais em uma gestão democrática efetivada na escola pública:

Eu acredito sim que a escola pode ser gerida de forma democrática, porque é o trabalho conjunto, com todos os envolvidos na escola. E a primeira coisa que se trabalha é a participação, se você não conseguir ter a participação de todos, jamais você vai ter a democracia [Gestor da Escola 5].

Entre os gestores entrevistados apareceu de forma muito clara a percepção comum entre eles, de que a escola não lhes pertence, mas pertence à comunidade. O que pode ser um indicativo interessante de compromisso com o que é coletivo e mesmo com a posteridade.

Com certeza, porque a escola não é do diretor, mas é da comunidade, da equipe de professores, pois sem eles não conseguimos nada. Então é importante nós trabalharmos em equipe e a responsabilidade de cada um é muito importante, inclusive a cozinheira também, pois todos fazem parte da educação da criança, que é objetivo maior da escola [Gestor da Escola 7].

Estes são apenas alguns pontos, entre outros não citados neste texto, que se observou e que indicaram práticas com conteúdos democráticos, na mesma perspectiva dos pressupostos que estão presentes na democracia deliberativa de que tratam Habermas (1995) e Elster (2001; 2007): responsabilidade no exercício do papel social; trabalho em conjunto. Isso pareceu indicar a construção de soluções para problemas comuns e também a responsabilidade de atuar em um espaço que pertence ao coletivo.

\section{A democracia na visão dos diretores de escola}


A finalidade da segunda categoria "a democracia na visão dos diretores de escola" foi analisar como os gestores entendiam, ou quais eram seus pensamentos, por democracia, e como seria possível este regime de governo servir de exemplo para constituir um modelo de gestão que se caracterizasse como democrático na escola pública. Percebemos que muito embora não houvesse uma preocupação em citar autores ou teorias democráticas específicas, estes gestores realizavam práticas de claro conteúdo democrático. Inclusive, criando outros espaços de diálogo não oficial para discutir e construir soluções provisórias para as demandas escolares. Foi o que o gestor da Escola 3 chamou de política do cafezinho:

Então, os espaços a gente procura nos HTPC, nas reuniões pedagógicas, às vezes em horário de café. Quando a gente está conversando e surge algum assunto e já começa a discussão e troca de ideias; mesmo nos corredores, que às vezes conversarmos, acaba-se tomando algumas decisões ali no corredor, porque eu acho que a gente não pode perder as oportunidades [Gestor da Escola 3 - grifos nossos].

Houve forte valorização desses espaços não oficiais por parte de outros os gestores também, chegando inclusive a tornar-se um espaço de formação e de divulgação de informação e conhecimentos úteis, devido ao tipo de importância dada a essas relações políticas dentro da escola:

Eu disse para a coordenadora, eles têm por legislação 15 min de café diariamente, tanto no período da manhã quanto no da tarde; então eu solicitei uma formação, uma vez por semana, e ela leva um texto, enquanto eles estão tomando um cafezinho, vão ouvindo algumas coisas interessantes ou que a própria mídia divulgou, alguma coisa de uma revista cientifica, que vai servir para o aprendizado deles [Gestor da Escola 9].

Ficou evidenciado que para estes gestores que foram entrevistados, a democracia brasileira, tanto em relação a administração do país quanto gestão na escola, ainda há uma forte luta para superar as antigas práticas autoritárias e centralizadoras que constituíram a história social, política e econômica do Brasil:

Acredito que com o tempo se consiga chegar lá, mas por enquanto nós só falamos de democracia. A nossa experiência democrática é curta. (...) porque estamos num aprendizado e não posso dizer que isso aconteça com perfeição, mas investimos para isso [Gestor da Escola $1]$. 
Estas práticas podem representar um conceito interessante que é o de "saber informulado" (OAKESHOTT, 1984, p. 83), isto é, mesmo na ausência momentânea de uma definição conceitual clara, a gestão se caracterizava por fortes elementos democráticos. A análise realizada a partir desta segunda categoria mostrou a criatividade, às vezes até mesmo um tanto quanto desorganizada (não no sentido pejorativo) de alguns gestores, na construção de soluções as mais democráticas possíveis para as demandas diárias das escolas em que estavam atuando.

\section{Políticas Educacionais e Gestão Democrática}

Por fim, a terceira categoria "políticas educacionais e gestão democrática" foi desenvolvida com o propósito de analisar, nos relatos dos gestores, de que forma as práticas que eram consideradas democráticas se fortaleciam na escola, tendo como pano de fundo as Políticas Públicas e a gestão escolar. Democratizar a escola é compreendêla como um sistema aberto, é constituir processos de liderança que estejam à altura das transformações sociais necessárias, relacionando a realidade local e global com os conteúdos estudados pelos discentes, na perspectiva de formação dos cidadãos e dos trabalhadores brasileiros como determina a Lei das Diretrizes e Bases da Educação Nacional (LDBEN) - Lei 9394/1996, em seu Artigo $2^{\circ}$ :

A educação, dever da família e do Estado, inspirada nos princípios de liberdade e nos ideais de solidariedade humana, tem por finalidade o pleno desenvolvimento do educando, seu preparo para o exercício da cidadania e sua qualificação para o trabalho. (BRASIL, 1996).

Os desafios para uma gestão democrática são enormes e devem ser enfrentados a todo tempo, em todos os espaços e das mais variadas formas. Sabe-se que isso não acontece rapidamente e de maneira fácil, mas as práticas democráticas podem proporcionar um maior contato e um melhor entendimento dos problemas, angustias e anseios enfrentados pela Educação Básica em um país com as características formativas do Brasil.

Nesse sentido, muito embora a gestão democrática seja uma determinação legal no termos do artigo 206, inciso VI, da Constituição Federal (BRASIL, 1988) e também do artigo $3^{\circ}$, inciso VII, da Lei de Diretrizes e Bases, a LDB (BRASIL, 1996), sabe-se que a lei por si só não cria e nem poderia criar uma democracia. Aliás, a ideia de 
instituir a democracia por lei, parece ter sido uma das características de países, como o Brasil, caracterizado por relações de natureza altamente centralizadoras e autoritárias. Nesta perspectiva, nenhuma sociedade vive de mera imposição de leis (direito), pois isso seria característica de um modelo ditatorial e não democrático, mas da aplicação contextualizada das leis enquanto direito positivado. Nesse sentido, autoridades de todos os âmbitos da vida nacional, incluindo-se os gestores das escolas públicas, fortalecem processos democráticos ao contextualizarem e atualizarem as relações entre as leis e as demandas de suas respectivas áreas de atuação.

Esta perspectiva apresentada acima indica que o gestor não é um simples executor de determinações legais, seja da secretaria municipal, da diretoria de ensino no caso do estado federado ou mesmo da União. Ele é o mediador entre a letra da lei e as práticas diárias. Assim, efetivam-se práticas com perspectivas democráticas ou a democracia no interior da escola pública. Destacamos duas falas:

Muitas coisas já vêm prontas da Secretaria Municipal de Educação, mas eu acho que o gestor deve promover um crescimento nas pessoas que estão trabalhando com ele, isso faz parte do trabalho de um bom gestor, e trabalhar sempre assim: ação, reflexão e ação (...). A participação é diferente, as tomadas de decisão a partir desse momento de ação, reflexão, ação são tomadas em conjunto respeitando sempre a hierarquia [Gestor da Escola 5].

As decisões são tomadas nos HTPCs e em reunião pedagógica. Sondamos a opinião dos professores, dos funcionários o que eles pensam e depois a equipe gestora fala e coloca o bom senso em relação ao relato das falas. Porque muitas vezes a gente está na administração, mas não percebe certas coisas que os outros percebem. (...) [Gestor da Escola 7].

Em seus relatos, os diretores nos deram uma amostra de que estavam atentos ao cumprimento das suas obrigações legais e, não somente estas, mas, também, à realidade de seu ambiente de trabalho e da realidade de entorno, pois não se sentiam simples executores da lei, mas profissionais que estavam procurando mediar soluções, muitas vezes, de formas criativas.

\section{Considerações Finais}


Ao analisarmos os relatos e práticas dos gestores de escolas públicas que foram entrevistados, concluímos que estes, de alguma forma, desenvolviam práticas de natureza bastante democráticas e que convergiam com princípios e pressupostos, segundo Habermas (1995) de uma democracia deliberativa. Estas práticas, muitas vezes bastante criativas como foi o caso da política do cafezinho que tinham objetivos, como: estimular o diálogo de maneira informal, e propiciar a inclusão e o respeito ao outro, na participação de todos, mesmo quando havia diferenças de nível social e de formação inicial entre estes agentes.

Ao refletirmos sobre concepções que imbricam nas escolas públicas brasileiras e seu funcionamento, duas questões sobre a organização do trabalho do diretor escolar precisam ser debatidas: uma primeira, segundo Paro (2000), está na dicotomia do trabalho administrativo e pedagógico; e uma segunda, conforme apontam os autores Lima (2011), Paro (2000) e Libâneo (2013), está relacionada com a discussão sobre a participação de todos os envolvidos com a escola para constituir propostas pedagógicas coletivas de trabalho com foco na aprendizagem dos estudantes.

Consideramos que o trabalho administrativo seja fundamental para o funcionamento racional e burocrático em que está envolvida a escola, mas essa dimensão deve estar atrelada e dando suporte ao trabalho pedagógico. Cabe aos diretores a organização do trabalho de modo a articular os níveis administrativo e pedagógico, onde o primeiro organiza, administra, executa em função do segundo. Organizar o trabalho da escola considerando as necessidades administrativas e saber como desenvolver o trabalho pedagógico com articulação entre o administrativo e o pedagógico é uma tarefa árdua para o diretor de escola e requer uma formação inicial e continuada desses profissionais. Acreditamos na ideia de trabalho coletivo e a escola é um local onde existem interesses de grupos; questões relacionadas ao autoritarismo, ou a autoridade do diretor; entre outras problemáticas que ainda devem ser resolvidas, pois a convivência escolar, geralmente, não dá de forma harmonia.

Segundo Lima (2011), além das questões relacionadas com interesses de grupos, também existem cidadãos que são movidos por interesses pessoais - o que os levam a participar e/ou não participar. Esse tipo de conduta interfere na busca pelo trabalho coletivo, na construção e execução de um projeto de escola, enfim na perspectiva de uma gestão democrática na escola.

Libâneo (2013) assinala alguns aspectos que podem ser considerados nas mudanças das práticas de gestão escolar, tendo em vista a gestão democrática e 
participativa, a serviço do processo ensino-aprendizagem: as práticas de organização e gestão devem estar voltadas à aprendizagem dos alunos; a qualidade do ensino depende do exercício eficaz da direção e da coordenação pedagógica; a organização e a gestão implicam a gestão com participação; a existência de um projeto pedagógico-curricular bem concebido e executado de forma eficaz; a atividade conjunta dos professores na elaboração e avaliação das atividades de ensino; a gestão da escola atrelada a atividades de formação continuada.

Longe de querermos generalizar os resultados e análises desta investigação, podemos afirmar de forma positiva a questão da gestão democrática nas escolas públicas brasileiras. Obviamente, não se assume aqui nenhum posicionamento acrítico ou ingênuo, visto que a escola pública e a gestão escolar não são melhores ou piores do que no passado, mas podemos dizer que são diferentes. Essas diferenças estão alicerçadas, principalmente, em perceber a democracia como processo, algo que é construído cotidianamente, uma alternativa válida e desejável.

Compreender e conceber democracia e/ou gestão democrática significa buscar processos de construções coletivas, de soluções para demandas reais. Os profissionais da educação tinham essa visão de que a gestão escolar deveria ser desenvolvida por meio de um trabalho participativo, baseado no conceito de liderança distributiva, num contexto educativo que acredita na democracia deliberativa, na participação ativa e na partilha de poder. Segundo Paro (2011), a democratização se faz na prática, é um exercício do dia a dia. Diante dos fatores que influenciam esse exercício democrático no cotidiano:

A escola pública, como acontece em geral com as instituições numa sociedade autoritária, é organizada com vistas a relações verticais, de mando e submissão, em detrimento das relações horizontais, de cooperação e solidariedade entre as pessoas (PARO, 2000, p.22).

As escolas públicas brasileiras ainda necessitam vivenciar mais experiências democráticas, de forma concreta, com vistas a servir como estímulo e adequação para novas teorias e práticas democráticas, uma vez que, não há e nem pode haver um modelo único de democracia que sirva para todas as escolas, e nem para os mais diferentes países.

\section{Referências}


ARISTÓTELES. Política. Tradução de Mário da Gama Kury. 2.ed. Brasília: UnB, 1988.

BRASIL. Constituição (1988). Constituição da República Federativa do Brasil. Texto constitucional promulgado em 5 de outubro de 1988, com as alterações adotadas pelas Emendas Constitucionais $n^{\circ} 1 / 1992$ a 64/2010 e pelas Emendas Constitucionais de Revisão $n^{\circ} 1$ a 6/1994. Brasília: Senado Federal, Subsecretaria de Edições Técnicas, 2010.

Lei de Diretrizes e Bases da Educação Nacional, nº 9394. (1996). Estabelece as diretrizes e bases da educação nacional. Brasília, DF.

CARVAlHO J. M. de. A Construção da Ordem: a elite política imperial. Rio de Janeiro: Editora UFRJ, 1996.

CONSTANT, B, Da Liberdade dos Antigos Comparada à dos Modernos. Tradução de Loura Silveira. Revista de Filosofia Política, Porto Alegre, no 2, p. 9-25, 1985.

ELSTER, J. La democracia deliberativa. Barcelona: Editorial Gedisa, 2001.

ELSTER, J. O mercado e o fórum: três variações na teoria política. In WERLE D. L.; MELO, R. S. (Org.). Democracia deliberativa. São Paulo: Editora Singular. 2007.

FAORO, R. Os donos do poder: formação do patronato político brasileiro. $3^{\mathrm{a}}$ edição. São Paulo: Editora Globo, 2001.

HABERMAS, J. Três modelos normativos de democracia. Revista Lua Nova, n. 36, p. 39-53, 1995.

HABERMAS, J. Teoria y práxis: estudios de filosofia social. $3^{\text {a }}$ edición. Traducción: Salvador Mas Torres (Introducciones y Capítulos 1 a 7) y Carlos Moya Espí (Capítulos 8 11 y Anexo). Madrid. Edictorial Tecnos, 1997.

HABERMAS, J. Direito e democracia: entre facticidade e validade. V. II. $2^{\mathrm{a}}$ edição. Tradução Flávio Beno Siebeneichler. Rio de Janeiro, 2003.

HABERMAS, J. O discurso filosófico da modernidade: doze lições. Tradução de Luiz Sergio Repa e Rodnei Nascimento. São Paulo: Martins Fontes, 2002.

HABERMAS, J. Teoria de la acción comunicativa: Tomo I: racionalidad de la acción y racionalización social e, Tomo II crítica de razón fucionalista. Traducción de Manuel Jiménez Redondo. Madrid: Editorial Trotta, 2010.

LEAL, V. N. Coronelismo, enxada e voto: o município e o regime representativo no Brasil. 2.ed. São Paulo: Alfa-Omega, 1975.

LIMA, L. LIMA, L. C. A escola como organização educativa. $4^{\text {a }}$ edição, São Paulo: Cortez, 2011. 
LIBÂNEO, J. C. LIBÂNEO, José Carlos. Organização e gestão da escola: teoria e prática. 6 ${ }^{a}$ Edição, São Paulo: Editora Heccus, 2013.

MÁRMOL, J. L. M. Democracia y deliberación: una reconstrucción del modelo de Jon Elster. Revista de estúdios políticos nueva época, n. 113, 2001.

OAKESHOTT, M. Rationalism in politics and other essays. Londres: Methuen, 1984.

PARO, V. H. Gestão democrática da escola pública. 3. ${ }^{\text {a }}$ ed. - São Paulo: Ática, 2000.

SARTORI, G. ¿Qué es la democracia? Traducción de Miguel Ángel Gonzáles Rodríguez y María Cristina Pestellini Laparelli Salamon. Azcapotzalco. México: Editorial Patria, 1993.

SCHWARTZMAN, S. As Bases do Autoritarismo Brasileiro. 3.ed. Rio de Janeiro: Campus, 1998.

TORRES, J. C. B. Figuras do Estado Moderno: Elementos para um estudo históricoconceitual das formas fundamentais de representação política no ocidente. São Paulo: Ed. Brasiliense.

URICOECHEA, F. O Minotauro Imperial: a burocratização do Estado patrimonial brasileiro no século XIX. Rio de Janeiro: Difel.

VIANNA, O. Populações Meridionais do Brasil: populações rurais do Centro-Sul. Niterói: EDUFF, vol. 1.

\section{Como referenciar este artigo}

LUIZ, Maria Cecília et al. Políticas públicas brasileiras e práticas democráticas de diretores escolares. Revista on line de Política e Gestão Educacional, Araraquara, v.20, n.2, p. 185-201, 2016. Disponível em: <http://dx.doi.org/10.22633/rpge.v20.n2.9459>. ISSN: 1519-9029.

Submetido em: maio/2016

Aprovado em: dez/2016 